\title{
Systemic Inflammatory Response After Preoperative Chemoradiotherapy Can Affect Oncologic Outcomes in Locally Advanced Rectal Cancer
}

\author{
IN HEE LEE ${ }^{1 *}$, SOYOON HWANG ${ }^{1 *}$, SOO JUNG LEE ${ }^{1}$, BYUNG WOOG KANG ${ }^{1}$, \\ DONGWON BAEK ${ }^{1}$, HYE JIN KIM ${ }^{2}$, SU YEON PARK ${ }^{2}$, JUN SEOK PARK ${ }^{2}$, \\ GYU SEOG CHOI ${ }^{2}$, JAE CHUL $\mathrm{KIM}^{3}$, SEUNG HYUN CHO ${ }^{4}$ and JONG GWANG KIM ${ }^{1}$ \\ ${ }^{1}$ Department of Oncology/Hematology, Kyungpook National University Medical Center, \\ Kyungpook National University School of Medicine, \\ Kyungpook National University Cancer Research Institute, Daegu, Republic of Korea, \\ ${ }^{2}$ Department of Surgery, Kyungpook National University Medical Center, \\ Kyungpook National University School of Medicine, Daegu, Republic of Korea; \\ ${ }^{3}$ Department of Radiation oncology, Kyungpook National University Hospital, \\ Kyungpook National University School of Medicine, Daegu, Republic of Korea; \\ ${ }^{4}$ Department of Radiology, Kyungpook National University Medical Center, \\ Kyungpook National University School of Medicine, Daegu, Republic of Korea
}

\begin{abstract}
Aim: Systemic inflammatory response (SIR) has been reported to be an important determinant of disease progression and survival in patients with colorectal cancer. This study investigated the prognostic relevance of changes in the platelet count on survival and the predictive value of changes in platelet/lymphocyte ratio (PLR) and neutrophil/lymphocyte ratio (NLR) on the pathological tumor response to preoperative chemoradiotherapy (CRT) in patients with locally advanced rectal cancer (LARC). Patients and Methods: From 2006 to 2015, 291 consecutive patients with LARC who were treated with preoperative CRT followed by curative surgery at the Kyungpook National University Medical Center (Daegu, Korea) were retrospectively analyzed. A cut-off value of $370 \times 10^{3} / \mu l$ for the platelet count was used and a PLR $\geq 235$ was defined as high. Any change in the PLR or NLR was calculated based on subtracting the pre-CRT PLR or NLR from the post-CRT
\end{abstract}

*These Authors contributed equally to this study as first authors.

Correspondence to: Jong Gwang Kim, MD, Ph.D., Department of Oncology/Hematology, Kyungpook National University Medical Center, Kyungpook National University School of Medicine, Kyungpook National University Cancer Research Institute, 807 Hogukno, buk-gu, Daegu 702-210, Republic of Korea. Tel: +82 532002623, Fax: +82 532002029, e-mail: jkk21c@knu.ac.kr

Key Words: Rectal cancer, platelet/lymphocyte ratio, chemoradiotherapy, predictive marker. values. Results: A total of $17.5 \%$ patients had stage II and $82.5 \%$ had stage III LARC. Initially high NLR and PLR were significantly associated with poor clinical outcomes. Patients who maintained a high platelet count after CRT also had an advanced pathological stage $(p=0.028)$, low pathological complete response rate $(p=0.048)$, and high relapse rate $(p=0.021)$. For patients with an initially low PLR, the multiple logistic regression analysis revealed that a high PLR change (odds ratio $(O R)=2.301$, 95\% confidence interval $(C I)=1.269-4.174 ; p=0.006)$ and clinical stage $I I$ compared to stage III (OR=1.878, 95\% CI=1.231-2.865; $p=0.003$ ) were significant independent markers predictive of a good response to CRT. Conclusion: The present results suggest that platelet and PLR change after preoperative $C R T$, along with the initial platelet count, can be used as prognostic and predictive markers for the oncological outcomes in patients with LARC.

Preoperative chemoradiotherapy (CRT) followed by total mesorectal excision is the standard treatment for locally advanced rectal cancer (LARC). Preoperative CRT leads to clinically meaningful tumor regression, including pathological complete response (CR) in $8-30 \%$ of patients (1). Several studies have found that a good pathological response after CRT improves the clinical outcome when compared to a poor response (2). However, since the tumor response to preoperative CRT varies among patients, predictive factors need to be identified to help clinicians develop risk-adapted treatment strategies. 
The systemic inflammatory response (SIR), including Creactive protein (CRP), Glasgow prognostic score (GPS) consisting of the CRP and serum albumin, neutrophil to lymphocyte ratio (NLR), and platelet to lymphocyte ratio (PLR), has been reported as an important determinant of disease progression and survival in patients with colorectal cancer (3). An elevated NLR has also been associated with a poor tumor response and unfavorable prognosis in patients with LARC (4). Plus, the PLR, reflecting both the inflammatory and the coagulation status, has been correlated with the progression of many tumors, including colorectal cancer (5-9). Platelets are already known to contribute to tumor growth, invasion, angiogenesis, and metastasis (10, 11). Thus, changes in the platelet count following chemotherapy were recently proposed as a potential marker for treatment response (12). However, the prognostic impact of changes in the platelet count and PLR after CRT in patients with rectal cancer has not yet been fully investigated.

Accordingly, this study investigated the association of the changes in the platelet count, PLR and NLR after CRT with the clinical outcomes in patients with LARC.

\section{Patients and Methods}

Patient eligibility. A retrospective database of 291 patients with pathologically confirmed, locally advanced rectal adenocarcinoma who completed preoperative CRT and underwent radical resection between January 2006 and October 2015 at Kyungpook National University Medical Center (Daegu, Korea) was analyzed.

The initial clinical stage was evaluated using total colonoscopy, computed tomography, pelvic magnetic resonance imaging, and whole-body positron emission tomography/computed tomography according to the seventh edition of the tumor, node, and metastasis (TNM) staging system 2010 (AJCC, 2010) (13). Longitudinal measurements of the neutrophil, lymphocyte, and platelet counts and the concentrations of serum carcinoembryonic antigen (CEA) and carbohydrate antigen 19-9 (CA19-9) were all assessed before and after CRT. The CRT consisted of 45 Gy delivered in 25 daily fractions over 5 weeks with concurrent 5 -fluorouracil $\left(425 \mathrm{mg} / \mathrm{m}^{2}\right)$ and leucovorin $\left(20 \mathrm{ng} / \mathrm{m}^{2}\right)$ on days 1-4 and 29-32. Total mesorectal excision was performed 6-8 weeks after the completion of CRT.

Definition of laboratory parameters. Blood samples were obtained from the patients on two separate occasions: during their first visit to the clinic (pre-CRT) and at 2 to 4 weeks before surgery (postCRT). For the platelet count, a cut-off value of $370 \times 10^{3} / \mu 1$ was selected according to a previous study (14), dividing the patients into low $\left(<370 \times 10^{3} / \mu \mathrm{l}\right)$ and high $\left(\geq 370 \times 10^{3} / \mu \mathrm{l}\right)$ groups. The NLR was calculated as the neutrophil count divided by the lymphocyte count and classified into two categories as low $(<5)$ or high $(\geq 5)$. When calculating the PLR, a PLR $\geq 235$ was defined as being high. Any change in the NLR or PLR was calculated by subtracting the pre-CRT NLR or PLR from the post-CRT values.

Statistical analysis. Relapse-free survival (RFS) was estimated from the time of surgery until the time of disease recurrence or death.
Table I. Patient characteristics $(N=291)$.

\begin{tabular}{|c|c|c|}
\hline Factors & Subgroup & $\mathrm{n}(\%)$ \\
\hline \multirow[t]{2}{*}{ Age } & $<65$ Years & $186(63.9)$ \\
\hline & $\geq 65$ Years & $105(36.1)$ \\
\hline \multirow[t]{2}{*}{ Gender } & Male & $203(69.8)$ \\
\hline & Female & $88(30.2)$ \\
\hline \multirow[t]{3}{*}{ Clinical T-stage } & II & $23(7.9)$ \\
\hline & III & $228(78.4)$ \\
\hline & IV & $40(13.7)$ \\
\hline \multirow[t]{2}{*}{ Clinical TNM } & II & $51(17.5)$ \\
\hline & III & $240(82.5)$ \\
\hline \multirow[t]{2}{*}{ Initial NLR } & $<5$ & $232(79.7)$ \\
\hline & $\geq 5$ & $28(9.6)$ \\
\hline \multirow[t]{2}{*}{ Initial PLR } & $<235$ & $232(79.7)$ \\
\hline & $\geq 235$ & $59(20.3)$ \\
\hline \multirow[t]{2}{*}{ CEA } & $<5 \mathrm{ng} / \mathrm{ml}$ & $182(62.5)$ \\
\hline & $\geq 5 \mathrm{ng} / \mathrm{ml}$ & $94(32.3)$ \\
\hline \multirow[t]{2}{*}{ CA19-9 } & $<37 \mathrm{U} / \mathrm{ml}$ & $217(74.6)$ \\
\hline & $\geq 37 \mathrm{U} / \mathrm{ml}$ & 54 (18.6) \\
\hline \multirow[t]{2}{*}{ Post-CRT NLR } & $<5$ & $212(72.9)$ \\
\hline & $\geq 5$ & $79(27.1)$ \\
\hline \multirow[t]{2}{*}{ Post-CRT PLR } & $<235$ & $116(39.9)$ \\
\hline & $\geq 235$ & $175(60.1)$ \\
\hline \multirow[t]{5}{*}{ Pathological T } & T0 & $42(14.4)$ \\
\hline & $\mathrm{T} 1$ & $9(3.1)$ \\
\hline & $\mathrm{T} 2$ & $55(18.9)$ \\
\hline & $\mathrm{T} 3$ & $172(59.1)$ \\
\hline & $\mathrm{T} 4$ & $13(4.4)$ \\
\hline \multirow[t]{2}{*}{ Pathological response $\mathrm{a}^{\mathrm{a}}$} & Good & $94(32.3)$ \\
\hline & Poor & $197(67.7)$ \\
\hline $\mathrm{pCR}$ & & $41(14.1)$ \\
\hline Relapse & & $91(31.3)$ \\
\hline
\end{tabular}

CEA: Carcinoembryonic antigen; CA19-9: carbohydrate antigen 19-9; NLR : neutrophil/lymphocyte ratio; PLR: platelet/lymphocyte ratio; CRT: chemoradiotherapy; pCR: pathological complete response. ${ }^{\mathrm{a} G o o d:}$ pCR, pT1, pT2; poor: pT3 or node-positive.

Overall survival (OS) was calculated from the date of diagnosis to death from any cause. Student's $t$-test and a Chi-square test were both applied to the qualitative variables. A logistic regression was used to determine a predictor of the pathologic tumor response. The survival analysis used the Kaplan-Meier method with a log-rank test. A multivariate analysis was performed using variables with a value of $p<0.1$ in a univariate analysis using Cox's proportional hazards model to derive a potentially suitable set of predictors. Twosided $p$-values of $<0.05$ were considered to be significant. The statistical analyses were performed using SPSS software version 18.0 (SPSS, Inc., Chicago, IL, USA).

\section{Results}

Patient characteristics. This study included 291 patients with LARC who received preoperative CRT followed by surgery. The baseline clinical demographics and laboratory findings are summarized in Table I. The median age of the patients was 59 years (range $=25-88$ years) and the ratio of males to 
Lee et al: Systemic Inflammatory Response After Preoperative Chemoradiotherapy

Table II. Association between clinicopathological features and the neutrophil/lymphocyte ratio (NLR): and platelet/lymphocyte ratio (PLR).

\begin{tabular}{|c|c|c|c|c|c|c|c|c|}
\hline \multirow[t]{2}{*}{ Factor } & \multicolumn{2}{|c|}{ NLR } & \multicolumn{2}{|c|}{ PLR } & \multicolumn{2}{|c|}{ Post CRT NLR } & \multicolumn{2}{|c|}{ Post CRT PLR } \\
\hline & Low & High & Low & High & Low & High & Low & High \\
\hline \multicolumn{9}{|l|}{ Gender } \\
\hline Male & $184(70.2)$ & $78(29.8)$ & $168(72.4)$ & $64(27.6)$ & $147(69.3)$ & 65 (30.7) & $85(73.3)$ & $31(26.7)$ \\
\hline Female & $18(64.3)$ & $10(35.7)$ & $35(59.3)$ & $24(40.7)$ & $56(70.9)$ & $23(29.1)$ & $118(67.4)$ & 57 (32.6) \\
\hline$p$-Value & \multicolumn{2}{|c|}{0.516} & \multicolumn{2}{|c|}{0.051} & \multicolumn{2}{|c|}{0.798} & \multicolumn{2}{|c|}{0.288} \\
\hline \multicolumn{9}{|l|}{ CEA } \\
\hline$<5 \mathrm{ng} / \mathrm{ml}$ & $166(66.4)$ & $16(64)$ & $148(67)$ & $34(61.8)$ & $139(68.5)$ & $43(58.9)$ & $73(65.8)$ & $109(66.1)$ \\
\hline$\geq 5 \mathrm{ng} / \mathrm{ml}$ & $84(33.6)$ & $9(36)$ & $73(33)$ & $21(38.2)$ & $64(31.5)$ & $30(41.1)$ & $38(34.2)$ & $56(33.9)$ \\
\hline$p$-Value & \multicolumn{2}{|c|}{0.809} & \multicolumn{2}{|c|}{0.471} & \multicolumn{2}{|c|}{0.139} & \multicolumn{2}{|c|}{0.0960} \\
\hline \multicolumn{9}{|l|}{ CA19-9 } \\
\hline$<37 \mathrm{U} / \mathrm{ml}$ & $201(81.7)$ & $16(66.7)$ & $181(83)$ & $36(67.9)$ & $159(79.9)$ & $58(80.6)$ & $91(82.7)$ & $126(78.3)$ \\
\hline$\geq 37 \mathrm{U} / \mathrm{ml}$ & $45(18.3)$ & $8(33.3)$ & 37 (17) & $17(32.1)$ & $40(20.1)$ & 14 (19.4) & $19(17.3)$ & 35 (21.7) \\
\hline$p$-Value & \multicolumn{2}{|c|}{0.102} & \multicolumn{2}{|c|}{0.014} & \multicolumn{2}{|c|}{0.905} & \multicolumn{2}{|c|}{0.366} \\
\hline \multicolumn{9}{|l|}{ Clinical TNM } \\
\hline II & $48(18.3)$ & $3(10.7)$ & 45 (19.4) & $6(10.2)$ & $35(16.5)$ & $16(20.2)$ & $22(18.9)$ & $29(16.6)$ \\
\hline III & $214(81.7)$ & $25(89.3)$ & $187(80.6)$ & $53(89.8)$ & $177(83.5)$ & $63(79.7)$ & $94(81)$ & $146(82.5)$ \\
\hline$p$-Value & \multicolumn{2}{|c|}{0.486} & \multicolumn{2}{|c|}{0.157} & \multicolumn{2}{|c|}{0.600} & \multicolumn{2}{|c|}{0.687} \\
\hline \multicolumn{9}{|l|}{ Pathologic T-stage } \\
\hline T0 & $41(15.6)$ & $0(0)$ & $39(16.8)$ & $3(5.1)$ & $28(13.2)$ & $14(17.7)$ & $16(13.8)$ & $26(14.9)$ \\
\hline $\mathrm{T} 1$ & $8(3.1)$ & $1(3.6)$ & $8(3.4)$ & $1(1.7)$ & $5(2.4)$ & $4(5.1)$ & $2(1.7)$ & $7(4.0)$ \\
\hline $\mathrm{T} 2$ & $53(20.2)$ & $2(7.1)$ & $47(20.3)$ & $8(13.6)$ & $40(18.9)$ & $15(19)$ & $16(13.8)$ & $39(22.3)$ \\
\hline $\mathrm{T} 3$ & $151(57.6)$ & $21(75)$ & $129(55.6)$ & $43(72.9)$ & $132(62.3)$ & $40(50.6)$ & $79(68.1)$ & $93(53.1)$ \\
\hline $\mathrm{T} 4$ & $9(3.4)$ & $4(14.3)$ & $9(3.9)$ & $4(6.8)$ & $7(3.3)$ & $6(7.6)$ & $3(2.6)$ & $10(5.7)$ \\
\hline$p$-Value & \multicolumn{2}{|c|}{0.006} & \multicolumn{2}{|c|}{0.053} & & & & \\
\hline $\mathrm{pCR}$ & & & & & & & & \\
\hline No & $222(84.7)$ & $28(100)$ & $194(83.6)$ & $56(94.9)$ & $185(87.3)$ & $65(82.3)$ & $100(86.2)$ & $150(85.7)$ \\
\hline Yes & $40(15.3)$ & $0(0)$ & $38(16.4)$ & $3(5.1)$ & 27 (12.7) & 14 (17.7) & $16(13.8)$ & 25 (14.3) \\
\hline$p$-Value & & & & & & & & \\
\hline Recurrence & & & & & & & & \\
\hline No & $185(70.6)$ & $14(50)$ & $168(72.4)$ & $32(54.2)$ & $147(69.3)$ & $53(67.1)$ & $82(70.7)$ & $118(67.4)$ \\
\hline Yes & $77(29.4)$ & $14(50)$ & $64(27.6)$ & $27(45.8)$ & $65(30.7)$ & $26(32.9)$ & $34(29.3)$ & 57 (32.6) \\
\hline$p$-Value & & & & & & & & \\
\hline
\end{tabular}

CRT: Chemoradiotherapy; CEA: carcinoembryonic antigen; CA19-9: carbohydrate antigen 19-9; pCR: pathological complete response.

females was approximately 7:3. The clinical stages before CRT were as follows: stage II $(\mathrm{n}=51,17.5 \%)$ and stage III $(\mathrm{n}=240,82.5 \%)$. After CRT, 41 patients $(14.1 \%)$ achieved pathologic CR and 91 patients $(31.3 \%)$ experienced relapse after CRT followed by surgical resection. Twenty-eight (9.6\%) patients had an initially high NLR and 59 patients (18.6\%) had a high PLR.

Association between initial NLR/PLR and clinical outcomes. A comparison between the clinicopathological characteristics of each group is shown in Table II. Initially high NLR and PLR were significantly associated with poor clinical outcomes, where the high-NLR group had a more advanced pathological T stage $(p=0.006)$ and experienced a higher relapse rate [odds ratio $(\mathrm{OR})=2.4,95 \%$ confidence interval $(\mathrm{CI})=1.09-5.27 ; p=0.025]$ than the low NLR group. In addition, the patients with an initially high PLR had a lower pathologic $\mathrm{CR}$ rate $(\mathrm{OR}=0.273,95 \% \mathrm{CI}=0.08-0.91 ; p=0.026)$ and higher rate of recurrence $(\mathrm{OR}=2.21,95 \% \mathrm{CI}=1.23-3.98$; $p=0.007)$. Notwithstanding this, the post CRT NLR and PLR were not associated with any oncological outcomes.

Association of change in platelet count with clinical outcomes. The patients were divided into three groups according to their pre- and post-CRT platelet count using a cut-off of $370 \times 10^{3} / \mu 1$ : low pre-CRT count, regardless of the post-CRT count (group A); high pre-CRT count and low post-CRT count (group B); high pre-CRT and post-CRT count (group C) (Table III). The patients who remained in the high platelet count group after CRT (group C) had advanced pathological stage $(p=0.028)$, low $\mathrm{CR}$ rate $(p=0.048)$, and high relapse rate $(p=0.021)$. The pathologic 
Table III. Association of change in platelet count with clinical outcomes in patients divided using a cut-off of $370 \times 10^{3} / \mu l$ : low prechemoradiotherapy (CRT) count, regardless of the post-CRT count (group A); high pre-CRT count and low post-CRT count (group B); high pre-CRT and post-CRT count (group C).

\begin{tabular}{lrccc}
\hline Factors & $\begin{array}{r}\text { Group A } \\
(\mathrm{n}=237)\end{array}$ & $\begin{array}{c}\text { Group B } \\
(\mathrm{n}=43)\end{array}$ & $\begin{array}{c}\text { Group C } \\
(\mathrm{n}=11)\end{array}$ & $p$-Value \\
\hline Clinical TNM & & & & \\
$\quad$ II & $46(19.4)$ & $4(9.3)$ & $1(9.1)$ & \\
$\quad$ III & $191(80.6)$ & $39(90.7)$ & $10(90.9)$ & 0.430 \\
Pathologic stage pCR & $39(16.5)$ & $2(4.7)$ & $0(0)$ & \\
$\quad$ I & $51(21.5)$ & $5(11.6)$ & $0(0)$ & \\
II & $77(32.5)$ & $17(39.5)$ & $6(54.5)$ & \\
III & $70(29.5)$ & $19(44.2)$ & $5(45.5)$ & 0.028 \\
pCR & & & & \\
$\quad$ No & $198(83.5)$ & $41(95.3)$ & $11(100)$ & \\
$\quad$ Yes & $39(16.5)$ & $2(4.7)$ & $0(0)$ & 0.048 \\
Recurrence & & & & \\
$\quad$ No & $170(71.7)$ & $26(60.5)$ & $4(36.4)$ & \\
$\quad$ Yes & $67(28.3)$ & $17(39.5)$ & $7(63.6)$ & 0.021 \\
CEA & & & & \\
$\quad<5 \mathrm{ng} / \mathrm{ml}$ & $152(67.6)$ & $25(59.5)$ & $5(55.6)$ & \\
$\quad \geq 5 \mathrm{ng} / \mathrm{ml}$ & $73(32.4)$ & $17(40.5)$ & $4(44.4)$ & 0.481 \\
CA19-9 & & & & \\
$\quad<37 \mathrm{U} / \mathrm{ml}$ & $184(82.9)$ & $30(73.2)$ & $3(37.5)$ & \\
$\geq 37 \mathrm{U} / \mathrm{ml}$ & $38(17.1)$ & $11(26.8)$ & $5(62.5)$ & 0.003 \\
\hline
\end{tabular}

CEA: Carcinoembryonic antigen; CA19-9: carbohydrate antigen 19-9; pCR pathological complete response.

CR rate after CRT was $0 \%$ in group $\mathrm{C}$ and $16 \%$ in group A, respectively. The estimated 5-year RFS and OS were also significantly different among the three groups (Table IV). The estimated 5-year RFS for groups A, B, and $\mathrm{C}$ was $67.1 \%, 53.8 \%$, and $30.7 \%$, respectively $(p=0.003)$. The estimated 5-year OS rate for group C $(42.4 \%)$ was the worst compared to that for groups A and B (78.8\% and $63.3 \%$, respectively, $p=0.002$ ) (Figure 1).

PLR changes and tumor response after CRT in the group with initially low PLR. In order to evaluate the relationship between the PLR changes and the tumor response after CRT, the patients with an initially low PLR $(\mathrm{N}=232)$ were selected for further analysis (Table V). The patients were classified using a cut-off value of 115 obtained from an SAS simulation analysis (post-CRT PLR minus pre-CRT PLR, low $<115$; high $\geq 115$ ). The changes in the PLR were significantly associated with pathological T-stage $(p=0.009)$, yet not associated with the pathological CR rate $(p=0.644)$ nor the relapse rate $(p=0.799)$. The multiple logistic regression analysis indicated that a high PLR change $(\mathrm{OR}=2.301,95 \%$ CI $1.269-4.174 ; p=0.006)$ and good clinical TNM stage (II vs. III: $\mathrm{OR}=1.878,95 \% \mathrm{CI}=1.231-2.865$; $p=0.003$ ) were significant independent predictive markers of
Table IV. Multivariate analysis of prognostic factors in patients divided using a cut-off of $370 \times 10^{3} / \mu l$ : low pre-chemoradiotherapy (CRT) platelet count, regardless of the post-CRT count (group A); high preCRT count and low post-CRT count (group B); high pre-CRT and postCRT count (group C).

\begin{tabular}{cccccc}
\hline & \multicolumn{2}{c}{ RFS } & & \multicolumn{2}{c}{ OS } \\
\cline { 2 - 3 } \cline { 5 - 6 } \cline { 5 - 6 } & HR( 95\% CI) & $p$-Value & & HR $(95 \% \mathrm{CI})$ & $p$-Value \\
\hline Group & & & & \\
$\mathrm{A}$ & $1(\mathrm{Ref})$ & 0.011 & & 1 (Ref) & 0.011 \\
$\mathrm{~B}$ & $1.61(0.94-2.77)$ & 0.084 & & $1.77(1-3.12)$ & 0.051 \\
$\mathrm{C}$ & $3.20(1.37-7.5)$ & 0.007 & & $3.17(1.33-7.56)$ & 0.010 \\
Age & Eliminated & & & Eliminated \\
CEA & Eliminated & & Eliminated \\
\hline
\end{tabular}

RFS: Relapse-free survival; OS: overall survival; HR: hazard ratio; CI: confidence interval; CEA: carcinoembryonic antigen.

Table V. The relationship between clinicopathological characteristics and platelet/lymphocyte ratio (PLR) changes after chemoradiotherapy ( $N=232$, initially low PLR).

\begin{tabular}{|c|c|c|c|c|}
\hline \multirow[t]{2}{*}{ Factor } & \multirow[t]{2}{*}{ Subgroup } & \multicolumn{2}{|c|}{ Change in PLR, n (\%) } & \multirow[t]{2}{*}{$p$-Value } \\
\hline & & $\begin{array}{l}\text { Low } \\
(<115)\end{array}$ & $\begin{array}{l}\text { High } \\
(\geq 115)\end{array}$ & \\
\hline \multirow[t]{2}{*}{ Age } & $<65$ Years & $89(68.5)$ & $61(60.4)$ & \\
\hline & $\geq 65$ Years & $41(31.5)$ & $41(40.2)$ & 0.171 \\
\hline \multirow[t]{2}{*}{ Gender } & Male & $95(73.1))$ & $73(71.6)$ & \\
\hline & Female & $35(26.9)$ & $29(28.4)$ & 0.799 \\
\hline \multirow[t]{2}{*}{ Clinical TNM } & II & $22(16.9)$ & $23(22.5)$ & 0.536 \\
\hline & III & $108(83.1)$ & $79(77.5)$ & \\
\hline \multirow[t]{5}{*}{ Pathologic T } & $\mathrm{T} 0$ & $20(15.4)$ & $19(18.6)$ & \\
\hline & $\mathrm{T} 1$ & $2(0.5)$ & $6(5.9)$ & \\
\hline & $\mathrm{T} 2$ & $22(16.9)$ & $26(24.5)$ & \\
\hline & $\mathrm{T} 3$ & $84(64.6)$ & $45(44.1)$ & \\
\hline & $\mathrm{T} 4$ & $2(1.5)$ & $7(6.9)$ & 0.009 \\
\hline \multirow[t]{2}{*}{$\mathrm{pCR}$} & No & $110(84.6)$ & $84(82.4)$ & \\
\hline & Yes & $20(15.4)$ & 18 (18.6) & 0.644 \\
\hline \multirow[t]{2}{*}{ Recurrence } & No & $95(73.1)$ & 73 (71.6) & \\
\hline & Yes & $35(26.9)$ & $29(28.4)$ & 0.799 \\
\hline \multirow[t]{2}{*}{ CEA } & $<5 \mathrm{ng} / \mathrm{ml}$ & $82(66.7)$ & $66(67.3)$ & \\
\hline & $\geq 5 \mathrm{ng} / \mathrm{ml}$ & $41(33.3)$ & $32(37.2)$ & 0.915 \\
\hline \multirow[t]{2}{*}{ CA 19-9 } & $<37 \mathrm{U} / \mathrm{ml}$ & $101(83.5)$ & $80(82.5)$ & \\
\hline & $\geq 37 \mathrm{U} / \mathrm{ml}$ & $20(16.5)$ & $17(17.5)$ & 0.846 \\
\hline \multirow[t]{2}{*}{ NLR } & $<5$ & $125(96.2)$ & $102(100)$ & \\
\hline & $\geq 5$ & $5(3.8)$ & $0(0)$ & 0.045 \\
\hline
\end{tabular}

pCR Pathological complete response, CEA: carcinoembryonic antigen; CA19-9: carbohydrate antigen 19-9; NLR: neutrophil/lymphocyte ratio.

a good response to CRT. However, the estimated 5-year RFS (65\% vs. 69.9\%; $p=0.999)$ and estimated 5 -year OS $(85.1 \%$ vs. 74\%; $p=0.408)$ were not significantly different between the two groups (Figure 2). 

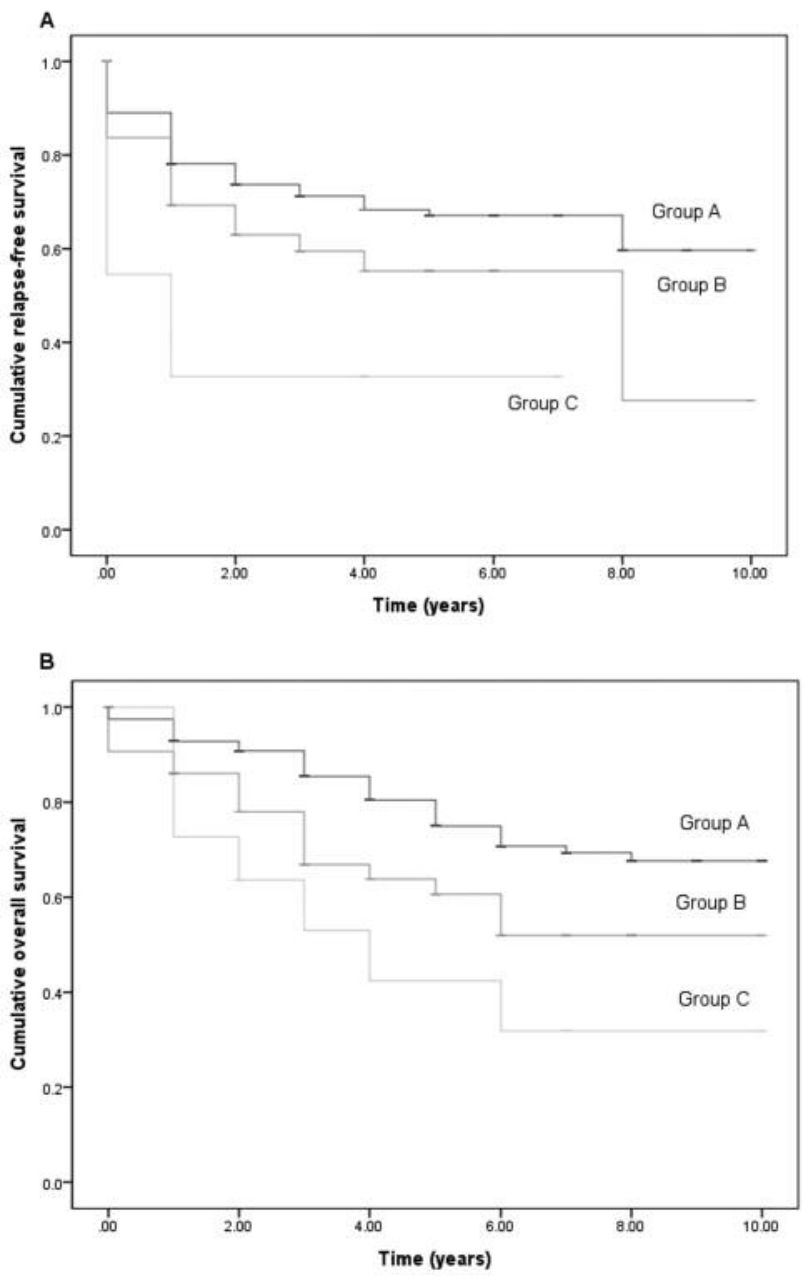

Figure 1. Kaplan-Meier cumulative relapse-free (RFS) (A) and overall $(O S)(B)$ survival curves according to change in platelet count. Patients were divided using a platelet count cut-off of $370 \times 10^{3} / \mu l$ : low prechemoradiotherapy (CRT) count, regardless of the post-CRT count (group A); high pre-CRT count and low post-CRT count (group B); high pre-CRT and post-CRT count (group C). A: 5-Year RFS for group A was $67.1 \%$ vs. group B of $53.8 \%$ vs. group C of $30.7 \%$ ( $p=0.003)$. B: 5 -Year OS group $A$ was $78.8 \%$ vs. group B of $63.3 \%$ vs. group $C$ of $42.4 \%(p=0.002)$.

\section{Discussion}

This study investigated the prognostic impact of platelet and PLR changes after CRT in a large population of patients with LARC, and found that changes in the platelet count and PLR did have a prognostic or predictive effect on the survival of the patients.

The association between inflammation and cancer was first described by Virchow in 1863 (15). Recognized as the 'seventh hallmark of cancer', inflammation contributes to tumor proliferation, angiogenesis, metastasis, defeats the
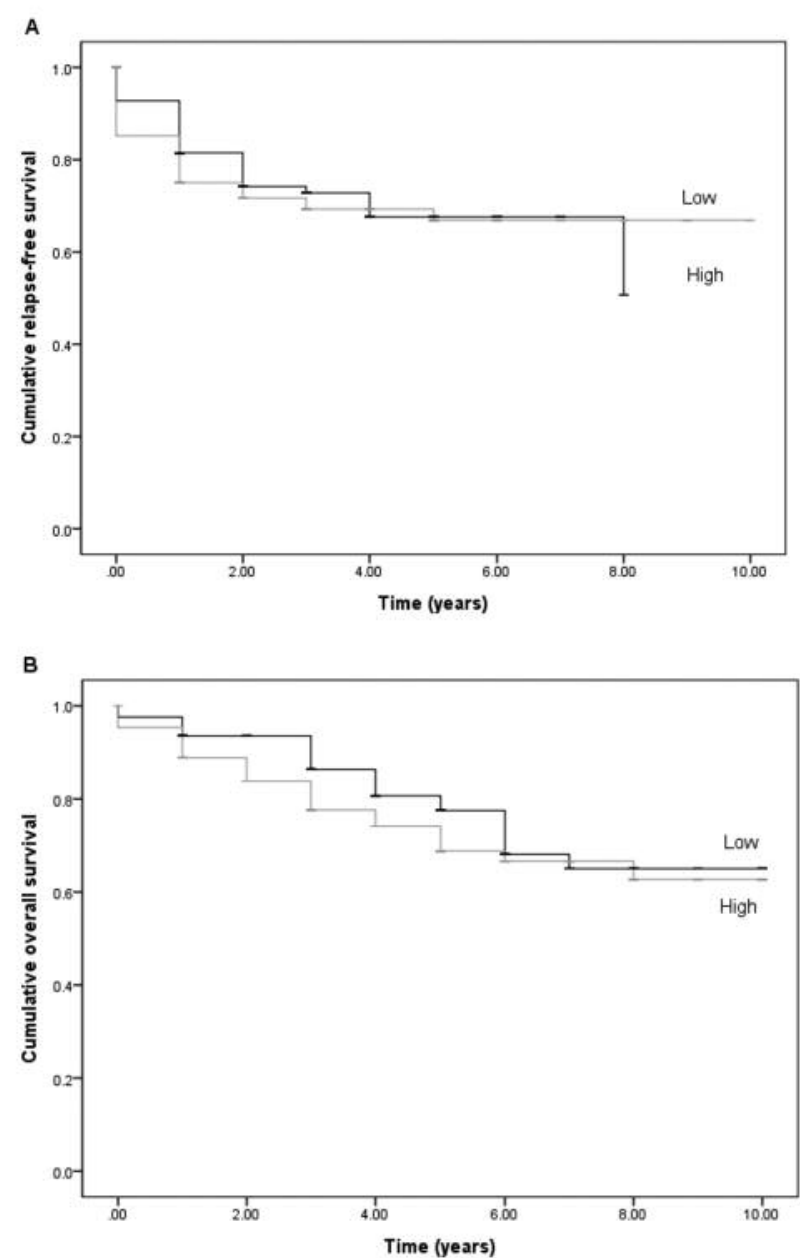

Figure 2. Kaplan-Meier cumulative relapse-free (RFS) (A) and overall $(O S)(B)$ survival curves according to change in platelet/lymphocyte ratio $(P L R)$ in patients with an initially low PLR $(N=232)$. Patients were divided using a cut-off 115 into low $(<115)$ and high $(\geq 115)$ change after chemoradiotherapy (CRT). A: 5-Year RFS for those with low PLR change was $65 \%$ vs. $69.9 \%$ for those with high PLR change ( $p=0.999)$. B: 5-Year OS for those with low PLR change was $85.1 \%$ vs. 74\% for those with high PLR change ( $p=0.408)$.

adaptive immune responses, and alters the response to treatment agents (16). Moreover, since the SIR is known to be associated with clinical outcome in a variety of malignancies (17), the laboratory parameters of the SIR, including the NLR and PLR, have already been investigated as prognostic or predictive markers in different cancer populations. The present study also found that an initially high NLR and PLR were poor prognostic factors for patients with LARC, which is consistent with previous studies on the prognostic value of the pre-operative assessment of the NLR and PLR in colorectal cancer $(3,18)$. 
The current study found that changes in the platelet count and PLR after CRT were prognostic or predictive marker of the pathological tumor response to preoperative CRT. Blood platelets are a key component linking the processes of hemostasis, inflammation and tissue repair (19). Pre-clinical animal models have shown that pharmacologically- or genetically-induced thrombocytopenia and platelet function defects are associated with reduced metastasis (20). In contrast, thrombocytosis is considered as an adverse prognostic factor in many types of solid cancers $(21,22)$, and previous studies demonstrated that initial thrombocytosis was a negative predictive factor for the pathological response and had an adverse impact on survival in rectal cancer (14). However, there have been relatively few studies that evaluated the clinical significance of a change in the platelet count after preoperative CRT in patients with rectal cancer, even though a change in the PLR after chemotherapy has already been correlated with the chemotherapy response in patients with gastric cancer (23). In the present study, the oncological outcomes were significantly associated with a change in the platelet count after preoperative CRT. For example, the patient group which maintained a high platelet count after CRT had worse estimated 5-year RFS (53.8\% vs. $30.7 \%)$ and OS $(63.3 \%$ vs. $42.4 \%)$ when compared to the group whose platelet count was low after CRT. Meanwhile, the group with initially low platelet count had better survival rates $(5$-year $\mathrm{RFS}=67.1 \%$, 5-year overall survival=78.8\%), regardless of their post-CRT platelet count. Therefore, a lower platelet count after preoperative CRT was correlated with an improved survival rate for the patients with LARC with an initially high platelet count.

While reduced T-lymphocyte count resulting in peripheral lymphopenia after radiotherapy was first described in the 1970s (24), the clinical significance of this phenomenon has not yet been fully evaluated. In this study, a considerable change in the PLR $(\geq 115)$ after preoperative CRT was identified as a significant independent predictive factor for achieving a good pathological stage in the group with initially low PLR $(\mathrm{OR}=2.301,95 \% \quad \mathrm{CI}=1.269-4.174$; $p=0.006)$. It would seem that the patients with a favorable response to CRT had a lower lymphocyte count after CRT due to the effect of radiation. Despite the decrease in the platelet count after CRT, the lymphocyte count dropped more than the platelet count. Thus, the post-PLR values for these patients decreased more after CRT than in the poor responders. To our knowledge, this is the first study evaluating the predictive impact of PLR changes on the tumor response after preoperative CRT in patients with LARC with an initially low PLR, although many studies have focused on the association of initially high levels of inflammatory markers with clinical outcomes in LARC.

The current study has certain limitations, including its retrospective nature and results that did not include both the
SIR and the local inflammatory response. The SIR and local characteristics of a tumor, including the well-investigated peritumoral infiltrate (Klintrup criteria) (25) and tumorinfiltrating lymphocytes (TILs) (26), all have an influence on disease progression. Although there were no significant differences in the CRT response according to the density of TILs after CRT, CRT can enhance the local immune response by increasing the number of TILs, and high TIL densities before treatment have already been associated with a good response to neoadjuvant CRT and a favorable prognosis (26). Accordingly, further investigation of TILs in tumor tissues is needed to elucidate the precise contribution of the host immune reaction to the response to CRT (27).

In conclusion, the present results suggest that changes in platelet count and PLR after preoperative CRT, along with the initial platelet count, can be used as prognostic and predictive markers for the oncological outcome in patients with LARC.

\section{Conflicts of Interest}

The Authors declare that they have no conflict of interest in regard to this study.

\section{Ethical Approval}

All procedures performed in studies involving human participants were in accordance with the ethical standards of the institutional and/or national research committee and with the 1964 Declaration of Helsinki and its later amendments or comparable ethical standards.

\section{Acknowledgements}

This work was supported by the National Research Foundation of Korea (NRF) grant funded by the Korea government (2014R1A5A2009242).

\section{References}

1 Sauer R, Becker H, Hohenberger W, Rodel C, Wittekind C, Fietkau R, Martus P, Tschmelitsch J, Hager E, Hess CF, Karstens JH, Liersch T, Schmidberger H and Raab R: Preoperative versus postoperative chemoradiotherapy for rectal cancer. N Engl J Med 351: 1731-1740, 2004.

2 Park IJ, You YN, Agarwal A, Skibber JM, Rodriguez-Bigas MA, Eng C, Feig BW, Das P, Krishnan S, Crane CH, Hu CY and Chang GJ: Neoadjuvant treatment response as an early response indicator for patients with rectal cancer. J Clin Oncol 30: 1770-1776, 2012.

3 Peng HX, Lin K, He BS, Pan YQ, Ying HQ, Hu XX, Xu T and Wang SK: Platelet-to-lymphocyte ratio could be a promising prognostic biomarker for survival of colorectal cancer: a systematic review and meta-analysis. FEBS Open Bio 6: 742-750, 2016.

4 Li MX, Liu XM, Zhang XF, Zhang JF, Wang WL, Zhu Y, Dong J, Cheng JW, Liu ZW, Ma L and Lv Y: Prognostic role of neutrophil-to-lymphocyte ratio in colorectal cancer: a systematic review and meta-analysis. Int J Cancer 134: 2403-2413, 2014. 
5 Lee S, Oh SY, Kim SH, Lee JH, Kim MC, Kim KH and Kim HJ: Prognostic significance of neutrophil lymphocyte ratio and platelet lymphocyte ratio in advanced gastric cancer patients treated with FOLFOX chemotherapy. BMC Cancer 13: 350, 2013.

6 Smith RA, Bosonnet L, Raraty M, Sutton R, Neoptolemos JP, Campbell $\mathrm{F}$ and Ghaneh P: Preoperative platelet-lymphocyte ratio is an independent significant prognostic marker in resected pancreatic ductal adenocarcinoma. Am J Surg 197: 466-472, 2009.

7 Templeton AJ, Ace O, McNamara MG, Al-Mubarak M, VeraBadillo FE, Hermanns T, Seruga B, Ocana A, Tannock IF and Amir E: Prognostic role of platelet to lymphocyte ratio in solid tumors: a systematic review and meta-analysis. Cancer Epidemiol Biomarkers Prev 23: 1204-1212, 2014.

8 Xie X, Luo KJ, Hu Y, Wang JY and Chen J: Prognostic value of preoperative platelet-lymphocyte and neutrophil-lymphocyte ratio in patients undergoing surgery for esophageal squamous cell cancer. Dis Esophagus 29: 79-85, 2016.

9 Ying HQ, Deng QW, He BS, Pan YQ, Wang F, Sun HL, Chen J, Liu $X$ and Wang SK: The prognostic value of preoperative NLR, d-NLR, PLR and LMR for predicting clinical outcome in surgical colorectal cancer patients. Med Oncol 31: 305, 2014.

10 Egan K, Crowley D, Smyth P, O'Toole S, Spillane C, Martin C, Gallagher M, Canney A, Norris L, Conlon N, McEvoy L, Ffrench B, Stordal B, Keegan H, Finn S, McEneaney V, Laios A, Ducree J, Dunne E, Smith L, Berndt M, Sheils O, Kenny D and O'Leary J: Platelet adhesion and degranulation induce prosurvival and pro-angiogenic signalling in ovarian cancer cells. PLoS One 6: e26125, 2011.

11 Sierko E and Wojtukiewicz MZ: Platelets and angiogenesis in malignancy. Semin Thromb Hemost 30: 95-108, 2004.

12 Stone RL, Nick AM, McNeish IA, Balkwill F, Han HD, Bottsford-Miller J, Rupairmoole R, Armaiz-Pena GN, Pecot CV, Coward J, Deavers MT, Vasquez HG, Urbauer D, Landen CN, Hu W, Gershenson H, Matsuo K, Shahzad MM, King ER, Tekedereli I, Ozpolat B, Ahn EH, Bond VK, Wang R, Drew AF, Gushiken F, Lamkin D, Collins K, DeGeest K, Lutgendorf SK, Chiu W, Lopez-Berestein G, Afshar-Kharghan V and Sood AK: Paraneoplastic thrombocytosis in ovarian cancer. N Engl J Med 366: 610-618, 2012.

13 Edge SB and Compton CC: The American Joint Committee on Cancer: the 7th edition of the AJCC cancer staging manual and the future of TNM. Ann Surg Oncol 17: 1471-1474, 2010.

14 Kim HJ, Choi GS, Park JS, Park S, Kawai K and Watanabe T: Clinical significance of thrombocytosis before preoperative chemoradiotherapy in rectal cancer: predicting pathologic tumor response and oncologic outcome. Ann Surg Oncol 22: 513-519, 2015.

15 Balkwill $\mathrm{F}$ and Mantovani A: Inflammation and cancer: Back to Virchow? Lancet 357: 539-545, 2001.

$16 \mathrm{Wu} \mathrm{Y}$ and Zhou BP: Inflammation: A driving force speeds cancer metastasis. Cell Cycle 8: 3267-3273, 2009.

17 McMillan DC: Systemic inflammation, nutritional status and survival in patients with cancer. Curr Opin Clin Nutr Metab Care 12: 223-226, 2009.
$18 \mathrm{Kim}$ IY, You SH and Kim YW: Neutrophil-lymphocyte ratio predicts pathologic tumor response and survival after preoperative chemoradiation for rectal cancer. BMC Surg 14: 94, 2014.

19 Klinger $\mathrm{MH}$ and Jelkmann W: Role of blood platelets in infection and inflammation. J Interferon Cytokine Res 22: 913922, 2002.

20 Camerer E, Qazi AA, Duong DN, Cornelissen I, Advincula R and Coughlin SR: Platelets, protease-activated receptors, and fibrinogen in hematogenous metastasis. Blood 104: 397-401, 2004.

21 Ikeda M, Furukawa H, Imamura H, Shimizu J, Ishida H, Masutani S, Tatsuta M and Satomi T: Poor prognosis associated with thrombocytosis in patients with gastric cancer. Ann Surg Oncol 9: 287-291, 2002.

22 Shimada H, Oohira G, Okazumi S, Matsubara H, Nabeya Y, Hayashi H, Takeda A, Gunji Y and Ochiai T: Thrombocytosis associated with poor prognosis in patients with esophageal carcinoma. J Am Coll Surg 198: 737-741, 2004.

23 Wang F, Liu ZY, Xia YY, Zhou C, Shen XM, Li XL, Han SG, Zheng Y, Mao ZQ, Gong FR, Tao M, Lian L and Li W: Changes in neutrophil/lymphocyte and platelet/lymphocyte ratios after chemotherapy correlate with chemotherapy response and prediction of prognosis in patients with unresectable gastric cancer. Oncol Lett 10: 3411-3418, 2015.

24 Stjernsward J, Jondal M, Vanky F, Wigzell H and Sealy R: Lymphopenia and change in distribution of human B- and Tlymphocytes in peripheral blood induced by irradiation for mammary carcinoma. Lancet 1: 1352-1356, 1972.

25 Roxburgh CS, Salmond JM, Horgan PG, Oien KA and McMillan DC: Comparison of the prognostic value of inflammation-based pathologic and biochemical criteria in patients undergoing potentially curative resection for colorectal cancer. Ann Surg 249: 788-793, 2009.

26 Teng F, Mu D, Meng X, Kong L, Zhu H, Liu S, Zhang J and Yu $\mathrm{J}$ : Tumor infiltrating lymphocytes (TILs) before and after neoadjuvant chemoradiotherapy and its clinical utility for rectal cancer. Am J Cancer Res 5: 2064-2074, 2015.

27 Galon J, Costes A, Sanchez-Cabo F, Kirilovsky A, Mlecnik B, Lagorce-Pages C, Tosolini M, Camus M, Berger A, Wind P, Zinzindohoue F, Bruneval P, Cugnenc PH, Trajanoski Z, Fridman WH and Pages F: Type, density, and location of immune cells within human colorectal tumors predict clinical outcome. Science 313: 1960-1964, 2006.
Received December 28, 2016

Revised February 14, 2017

Accepted February 21, 2017 